13,03

\title{
О механизме возбуждения плазменных колебаний в твердых телах, исследованных методом полного внешнего отражения рентгеновских лучей
}

\author{
(C) В.М. Стожаров, И.И. Хинич
}

Российский государственный педагогический университет им. А.И. Герцена, Санкт-Петербург, Россия

E-mail: gut1111@yandex.ru

Поступила в Редакцию 18 ноября 2020 г.

В окончательной редакции 18 ноября 2020 г.

Принята к публикации 11 января 2021 г.

Рассмотрен механизм возбуждения плазменных колебаний в твердых телах методом полного внешнего отражения рентгеновских лучей. Показано, что главную роль в возбуждении плазмонов в твердых телах играют медленные электроны, входящие благодаря вторично-электронному усилению в тонких поверхностных слоях твердого тела в состав многоэлектронных актов эмиссии в виде электронных пачек. Для карбида кремния проведен качественный расчет числа медленных вторичных электронов, порожденных рентгеновскими фотоэлектронам.

Ключевые слова: плазмон, плазменные колебания, электрон, электронная пачка, квантовый выход.

DOI: 10.21883/FTT.2021.05.50821.264

Новая методика полного внешнего отражения (ПВО) рентгеновских лучей основана на измерении интенсивности отраженных рентгеновских лучей при скользящем падении параксиального пучка рентгеновских лучей около $0.5^{\prime}$, сформированного параболическим зеркалом. Запись рентгенограммы ПВО в режиме $2 \theta-\theta$ обеспечивает получение дифференциальной кривой ПВО с максимумом [1-2]. Угловое положение этого максимума характеризует показатель преломления рентгеновских лучей и связанную с ним энергию плазменных колебаний [3]. Актуальность этой методики состоит в ее новом применении к исследованию дисперсии плазмонов в твердых телах, несущей информацию о их внутренних микронапряжениях, приводящих к деформации кристаллической решетки и электронной поляризации твердого тела [4].

Настоящая работа посвящена исследованию механизма возбуждения плазменных колебаний в твердых телах на основе работ по внешнему фотоэлектрическому эффекту в мягкой области рентгеновского спектра.

Следствием корпускулярно-волнового дуализма микрочастиц является резонансное взаимодействие между ними, которое становится особенно вероятным при совпадении их частот [5]. Этим объясняется большая вероятность возбуждения поверхностных и объемных плазмонов в случае упругого отражения медленных электронов с энергиями от 3 до $25 \mathrm{eV}$ от щелочноземельных и благородных металлов, исследованная в [6], а также резонансное возбуждение плазмонов лазерным излучением в видимой области электромагнитного спектра с энергией кванта порядка $5 \mathrm{eV}[7,8]$.

Для выяснения вопроса о механизме возбуждения плазмонов рентгеновскими лучами рассмотрены рабо- ты $[9,10]$ в которых содержатся результаты исследования внешнего рентгеновского фотоэффекта в мягкой области рентгеновского спектра. В этих работах показано, что благодаря вторично-электронному усилению в поверхностных слоях твердого тела в вакуум выходят многоэлектронные акты рентгеновской эмиссии в виде электронных пачек [9]. Каждая такая электронная пачка содержит один быстрый фотоэлектрон, возбужденный рентгеновским квантом из атома твердого тела, и несколько медленных вторичных электронов, которые эмитируются из тонкого поверхностного слоя твердого тела под действием этого быстрого фотоэлектрона. Вторично-эмиссионное происхождение электронных пачек подтверждено исследованиями энергетических спектров рентгеновской фотоэмиссии из твердых тел [10], в которых была обнаружена большая группа медленных электронов с энергиями менее $10 \mathrm{eV}$ подобно спектрам истинно вторичных электронов (ИВЭ), возбужденных первичным электронным пучком средних энергий [11]. В табл. 1 и 2 приведены результаты измерения средних численностей электронных пачек $v_{c}$, и рентгеновских квантовых выходов $\varkappa_{r}$ для металлов и диэлектриков.

Численность электронных пачек обусловлена медленными вторичными электронами, возбужденными быстрыми рентгеновскими фотоэлектронами из зоны выхода ИВЭ. Известно [11], что зона выхода ИВЭ из диэлектриков почти на порядок больше зоны выхода ИВЭ из металлов. Сравнение табл. 1 и 2 показывает аналогичное соотношение численности электронных пачек $v_{c}$, эмитируемых из металлов и диэлектриков.

Таким образом, механизм возбуждения плазменных колебаний в твердых телах методом ПВО рентгеновского излучения $\mathrm{Cu} K_{\alpha 1}$ с энергией кванта $8048 \mathrm{eV}$ опре- 
Таблица 1. Значения величин $\varkappa_{r}$ и $v_{c}$ для металлов, измеренные с использованием излучения $\mathrm{Cu} K_{\alpha}$

\begin{tabular}{c|c|c}
\hline Фотокатод & $\varkappa_{r}, \%$ & $\nu_{c}, \%$ \\
\hline $\mathrm{Al}$ & 0.42 & 15.5 \\
\hline $\mathrm{Ti}$ & 0.80 & 15.3 \\
\hline $\mathrm{Cr}$ & 1.10 & 15.0 \\
\hline $\mathrm{Fe}$ & 1.10 & 11.4 \\
\hline $\mathrm{Sn}$ & 1.45 & 11.7 \\
\hline $\mathrm{Au}$ & 2.04 & 6.0 \\
\hline $\mathrm{Pb}$ & 2.06 & - \\
\hline $\mathrm{Bi}$ & 1.71 & 11.3
\end{tabular}

Таблица 2. Значения величин $\varkappa_{r}$ и $v_{c}$ для диэлектриков, измеренные с использованием излучения $\mathrm{Cu} K_{\alpha}$

\begin{tabular}{c|c|c}
\hline Фотокатод & $\varkappa_{r}, \%$ & $v_{c}, \%$ \\
\hline $\mathrm{NaCl}$ & 0.60 & 25 \\
\hline $\mathrm{KCl}$ & 0.78 & 21 \\
\hline $\mathrm{KBr}$ & 0.80 & 27 \\
\hline $\mathrm{CsCl}$ & 2.00 & 60 \\
\hline $\mathrm{CsJ}$ & 2.30 & 70
\end{tabular}

Таблица 3. Значения $\varkappa_{r}$ и $\eta$

\begin{tabular}{c|c|c|c}
\hline Элемент & $\varkappa_{r}, \%$ & $\eta$ & $Z$ \\
\hline $\mathrm{Al}$ & 0.42 & 0.20 & 13 \\
\hline $\mathrm{Ti}$ & 0.80 & 0.30 & 22 \\
\hline $\mathrm{Au}$ & 2.04 & 0.45 & 79
\end{tabular}

деляется исключительно медленными электронами с наиболее вероятной энергией $(2-5) \mathrm{eV}$, возбужденными быстрыми рентгеновскими фотоэлектронами из зоны выхода $\lambda$ медленных ИВЭ.

В заключение проведем качественный расчет числа медленных вторичных электронов, порожденных фотоэлектронами, которые возбуждаются рентгеновским излучением $\mathrm{Cu} K_{\alpha 1}$, из эпитаксиальной пленки карбида кремния. Карбид кремния является широкозонным полупроводником и для политипа $3 C(\beta)$ кубической кристаллической структуры характеризуется шириной запрещенной зоны $\Delta E \sim 2.5 \mathrm{eV}$. Для такого расчета необходимо знать величину зоны выхода $\lambda$ медленных вторичных электронов, возбуждаемых быстрыми рентгеновскими фотоэлектронами. Для карбида кремния таких данных в литературе нет, но есть данные по вторичной электронной эмиссии широкозонного полупроводника селена [11] с шириной запрещенной зоны $\Delta E=2.7 \mathrm{eV}$ близкой к значению ширины запрещенной зоны карбида кремния. Определенная методом эквивалентной подложки зона выхода ИВЭ из селена составляет $\lambda=35 \AA$. Примем это значение зоны выхода медленных вторичных электронов, возбужденных рентгеновскими фотоэлектронами, за зону выхода медленных электронов для карбида кремния. В литературе также не содержится сведений о рентгеновском квантовом выходе $\varkappa_{r}$ для карбида кремния. Известно, что неупругое рассеяние электронов зависит только от порядкового номера элемента $Z$ [11]. В табл. 3 для трех элементов сопоставляются коэффициенты неупругого отражения электронов $\eta$ с квантовым выходом рентгеновских фотоэлектронов $\varkappa_{r}$, взятые из табл. 1.

Видно, что имеет место корреляция между значениями $\varkappa_{r}$ и $\eta$. Поэтому с хорошим приближением можно использовать в дальнейших расчетах для карбида кремния по данным табл. 1 величину квантового выхода рентгеновских фотоэлектронов $\varkappa_{r}=0.42 \%$ и среднюю численность электронной пачки $v_{c}=15.5 \%$ для алюминия, поскольку $Z$ алюминия близок к $Z$ карбида кремния.

Квантовый выход рентгеновских фотоэлектронов $\varkappa_{r}=0.42 \%$ означает, что один квант рентгеновского излучения в среднем порождает 0.0042 электрона. Из наших измерений ПВО рентгеновских лучей на рентгеновском дифрактометре ДРОН-7 с острофокусной рентгеновской трубкой и параболическим зеркалом следует, что интенсивность отраженного от поверхности при скользящем падении под углом $\alpha \sim 0.02^{\circ}$ рентгеновского излучения составляет $N_{2}=20000$ quant/s при интенсивности первичного излучения, падающего на образец, $N_{1}=66000$ quant/s. Уменьшение первичной интенсивности на $\Delta N=46000$ quant/s происходит в результате возбуждения фотоэлектронов, в первую очередь $K$-оболочки кремния с энергией $E_{\mathrm{ph}}=8048 \mathrm{eV}-1838 \mathrm{eV}=6210 \mathrm{eV}$ и оже-электронов с энергией $E_{\text {auger }}=1640 \mathrm{eV}$. При этом образуется 193 electron/s, а за время экспозиции $t=33 \mathrm{~min}=1980 \mathrm{~s}$ в слое карбида кремния $h=120 \AA$ образуются $n=382530$ electrons. Однако не все эти фотоэлектроны создадут пачку медленных вторичных электронов, а только те из них, которые дважды пересекут зону выхода $\lambda=35 \AA$ медленных ИВЭ. Учитывая этот факт, а также среднюю численность пачки медленных электронов для алюминия (табл. 1) и соотношение между $h$ и $\lambda$, рассчитывается число вторичных электронов $N_{\mathrm{SE}}$ по формуле

$$
N_{\mathrm{SE}}=\frac{2 \lambda}{h} v_{c} n=33470 \text { electrons }
$$

Таким образом, по грубой оценке число медленных вторичных электронов, возбуждающих плазменные колебания в тонком поверхностном слое карбида кремния толщиной $\lambda \sim 35 \AA$, составляет порядка 34000 . 


\section{Финансирование работы}

Работа выполнена в рамках государственного задания при финансовой поддержке Министерства науки и высшего образования РФ проект № 3.5005.2017/ВУ.

\section{Конфликт интересов}

Авторы заявляют, что у них нет конфликта интересов.

\section{Список литературы}

[1] В.М. Стожаров. ЖТФ 87, 1, 125 (2017).

[2] В.М. Стожаров, В.П. Пронин. ЖТФ 87, 12, 1901 (2017).

[3] В.М. Стожаров. ЖТФ 89, 7, 1042 (2019).

[4] В.М. Стожаров. ЖТФ 90, 7, 1116 (2020).

[5] Ч. Киттель. Квантовая теория твердых тел. Наука. М. (1967). 485 c.

[6] И.М. Бронштейн, И.Л. Краинский. Изв. АН СССР. Сер. физ. 40, 8, 1656 (1976).

[7] В.Б. Гильденбург, В.А. Костин, И.А. Павличенко. Вестн. Нижегородского ун-та им. И.А. Лобачевского 5, 3, 314 (2011).

[8] В.В. Климов. Наноплазмоника. Физматлит, М. (2009). $480 \mathrm{c}$.

[9] М.А. Румш, В.Н. Щемелев. ФТТ 5, 1, 71 (1963).

[10] В.Н. Щемелев, Л.Г. Елисеенко, Е.П. Денисов, М.А. Румш. ФTT 6, 9, 2574 (1964).

[11] И.М. Бронштейн, Б.С. Фрайман. Вторичная электронная эмиссия. Наука, М. (1969). 400 с.

Редактор Т.Н. Василевская 